\section{Commentary: Antifibrotic medications and wound healing after cardiac surgery}

\author{
Leora B. Balsam, MD
}

Antifibrotic medications compose a growing group of therapeutics aimed at stemming the course of disease processes with aberrant fibrotic response. ${ }^{1}$ One example is nintedanib (Ofev; Boehringer Ingelheim, Ingelheim am Rhein, Germany), an oral medication approved for treatment of idiopathic pulmonary fibrosis (IPF), systemic sclerosisassociated interstitial lung disease, and chronic fibrosing interstitial lung disease. This medication is an intracellular tyrosine kinase inhibitor that inhibits fibroblast proliferation and myofibroblast differentiation by blocking receptors of platelet-derived growth factor (PDGF), fibroblast growth factor (FGF), and vascular endothelial growth factor (VEGF).

Data on the direct effect of nintedanib on wound healing have not been published; however, it is reasonable to postulate that it may abrogate essential fibroblast response during wound healing. The manufacturer recommends that it be discontinued before major surgery, and this is likely an action that should be taken whenever possible with antifibrotic medications in general. Small studies have compared outcomes of patients with IPF undergoing lung transplantation that have taken the antifibrotic medications nintedanib and pirfenidone up to the time of lung transplantation with those of patients that have not. ${ }^{2,3}$ In one study of 266 patients, the incidence of early dehiscence of the bronchial anastomosis was significantly higher in the antifibrotic treatment group compared with the control group $(1.1 \%$ vs 0.5$) .^{2}$ Because the study was retrospective and characteristics of the 2

From the Division of Cardiac Surgery, UMass Memorial Medical Center, Worcester, Mass.

Disclosures: The author reported no conflicts of interest.

The Journal policy requires editors and reviewers to disclose conflicts of interest and to decline handling or reviewing manuscripts for which they may have a conflict of interest. The editors and reviewers of this article have no conflicts of interest.

Received for publication Nov 29, 2020; revisions received Nov 29, 2020; accepted for publication Dec 15, 2020; available ahead of print Dec 25, 2020.

Address for reprints: Leora B. Balsam, MD, Division of Cardiac Surgery, UMass Memorial Medical Center, University Campus, 55 Lake Ave North, Worcester, MA 01655 (E-mail: leora.balsam@umassmemorial.org).

JTCVS Techniques 2021;6:104-5

2666-2507

Copyright (c) 2021 The Authors. Published by Elsevier Inc. on behalf of The American Association for Thoracic Surgery. This is an open access article under the CC BY-NCND license (http://creativecommons.org/licenses/by-nc-nd/4.0/).

https://doi.org/10.1016/j.xjtc.2020.12.011

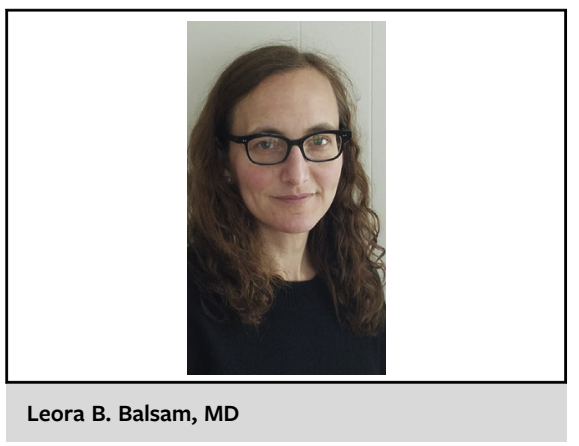

CENTRAL MESSAGE

Antifibrotic medications, a growing group of therapeutics for fibrotic pulmonary disease, may adversely affect wound healing in the post-cardiac surgery patient.

treatment groups were unmatched, the importance of this finding is unclear. In addition, because of the short halflife of nintedanib and pirfenidone (10-15 hours and 0.4 hours, respectively), and because these medications are not continued posttransplantation, an impact on wound healing is not likely to be seen in lung transplant recipients.

In this issue of the Journal, Drs He and Raman draw attention to the potential adverse impact of antifibrotic medications on wound healing in the post-cardiac surgery patient. ${ }^{4}$ They describe a case of sternal and radial artery harvest site dehiscence that developed in a patient with IPF who underwent coronary artery bypass grafting. The patient had continued treatment with nintedanib through the perioperative and postoperative period and presented with nonhealing of both wounds at 4 weeks of follow-up. Nintedanib was then discontinued, and reoperation was performed for sternal and soft tissue closure. Antifibrotic medication was not resumed in this case, even at 7 months of follow-up.

This particular case highlights a postoperative complication that may or may not have been related to the administration of an antifibrotic medication. The authors' point that one must systematically review the indications and potential contraindications for all medications in the perioperative and postoperative periods is valid. When considering antifibrotic medications, one must weigh the risks and benefits of their administration, given the lack of available data to guide treatment decisions in the perioperative and postoperative periods. In more severe cases of IPF, it is possible that discontinuation of the antifibrotic medication could 
lead to a rapid decline in lung function and/or acute exacerbation. With a median survival after diagnosis of 3 years, IPF is rapidly progressive, and one must carefully consider how interruption of antifibrotic medication may alter its course. In addition, candidacy for cardiac surgery in patients with advanced pulmonary disease must be thoughtfully considered by a multidisciplinary team that includes cardiac surgeons, cardiologists, and pulmonologists; it may be appropriate to pursue nonsurgical treatment when interruption of antifibrotic medication cannot be considered and disease severity is high.

\section{References}

1. Ahluwalia N, Seah BS, Tager AM. New therapeutic targets in idiopathic pulmonary fibrosis: aiming to rein in runaway wound-healing responses. Am J Respir Crit Care Med. 2014;190:867-78.

2. Mackintosh JA, Munsif M, Ranzenbacher L, Thomson C, Musk M Snell G, et al. Risk of anastomotic dehiscence in patients with pulmonary fibrosis transplanted while receiving antifibrotics: experience of the Australian Lung Transplant Collaborative. J Heart Lung Transplant. 2019;38: 553-9.

3. Leuschner G, Stocker F, Veit T, Kneidinger N, Winter H, Schramm R, et al Outcome of lung transplantation in idiopathic pulmonary fibrosis with previous antifibrotic therapy. J Heart Lung Transplant. 2018;37:268-74.

4. He C, Raman J. Wound dehiscence with nintedanib after cardiac surgery: a cautionary tale. J Thorac Cardiovasc Surg Tech. 2021;6:99-101. 